\title{
Lactose and galactose content in cheese results in overestimation of moisture by vacuum oven and microwave methods
}

\author{
H. Lee, ${ }^{\star}$ S. A. Rankin, ${ }^{\star 1}$ L. M. Fonseca, $†$ and F. X. Milani ${ }^{\star}$ \\ ${ }^{*}$ Department of Food Science, University of Wisconsin, Madison 53706 \\ †Coordenação de Aperfeiçoamento de Pessoal de Nível Superior (CAPES) and School of Veterinary Medicine, Universidade Federal de Minas \\ Gerais, Belo Horizonte-MG 31270-901, Brazil
}

\begin{abstract}
Moisture determination in cheese is a critical test for regulatory compliance, functionality, and economic reasons. Common methods for moisture determination in cheese rely upon the thermal volatilization of water from cheese and calculation of moisture content based on the resulting loss of mass. Residual sugars, such as lactose and galactose, are commonly present in cheeses at levels ranging from trace amounts to $5 \%$. These sugars are capable of reacting with other compounds in cheese, especially under the thermal conditions required for moisture determination, to yield volatile reaction products. The hypothesis of this work is that residual sugars in cheese will be converted into volatile compounds over the course of moisture determination at a level sufficient to result in overestimated cheese moisture. A full-factorial statistical design was used to evaluate the effects of cheese type, sugar type, sugar level, method type, and all interactions. Cheddar and low-moisture, part-skim (LMPS) Mozzarella cheeses were prepared with 1,3 , and $5 \%$ added lactose or galactose, and subjected to either vacuum oven or microwave-based moisture determination methods. Browning index and colorimetry were measured to characterize the color and extent of browning. Volatile analyses were performed to provide chemical evidence of the reactions proposed. The presence of residual sugars altered moisture calculations as a function of cheese type, sugar type, sugar level, method type, and numerous interactions. At higher concentrations of residual sugar, the percentage moisture determinations were increased by values of up to 1.8. Measures of browning reactions, including browning index, colorimetry, and volatile profiles demonstrate that the proposed browning reactions played a causative role. This work establishes the need to consider cheese type, sugar type, sugar levels, and
\end{abstract}

Received September 24, 2013.

Accepted January 26, 2014.

${ }^{1}$ Corresponding author: sarankin@wisc.edu method type as a means of more accurately determining moisture levels.

Key words: moisture, lactose, cheese

\section{INTRODUCTION}

Moisture in cheese is important from the regulatory, functional, and economic viewpoints. Accurate and precise measurement of cheese moisture is especially important to maximize yield and achieve economic parity. Standard methods for determining moisture involve volatilization of available water through the application of heat and vacuum (AOAC, 1990). Because cheese is a chemically complex and variable medium, composition-dependent volatiles may be created during this analysis. As these methods calculate moisture based on the relative loss of mass from drying, such volatiles, if created and volatilized in sufficient mass, would result in a moisture overestimation. For instance, composition-dependent volatiles may be created from residual sugars in cheese reacting with nitrogenous substrate through various browning reaction pathways.

Volatile compounds may be created during heating through various chemical reactions, such as Maillard browning (Hodge, 1953). The first stage of Maillard browning involves the condensation of a reducing sugar and an amino group to form an Amadori rearrangement product (ARP). Further reactions of ARP take place via 1,2/2,3-enolization or Strecker degradation. Low $\mathrm{pH}$ values are known to favor the formation of 5-hydroxymethyl-2-furaldehyde (HMF) via 1,2-enolization, whereas reductones, decomposition products, and Strecker aldehydes are preferred at a neutral or higher $\mathrm{pH}$ via 2,3-enolization or Strecker degradation.

Maillard browning between lactose and amines can result in the formation of lactones, aldehydes, furans, alcohols, acids, and sulfur-containing compounds (Ferretti and Flanagan, 1971). A generalized Maillard browning scheme under neutral $\mathrm{pH}$ may form maltol (Labuza, 1994) or Strecker degradation products such as Strecker aldehydes (Hodge, 1953). The amount of residual sugar in cheese may be up to $5 \%$ of the total 
mass, depending on the variety of cheese and extent of fermentation. Quantitatively, $1 \mathrm{~mol}$ of lactose reacted with equimolar lysine can yield up to $1 \mathrm{~mol}$ of maltol and $2 \mathrm{~mol}$ of water. Thus, $5 \mathrm{~g}$ of lactose in $100 \mathrm{~g}$ of cheese may result in the generation of up to $1.84 \mathrm{~g}$ of maltol and $0.53 \mathrm{~g}$ of additional water. These reaction products, if completely volatilized, would result in a $2.37 \mathrm{~g}$ of additional loss of mass and an overestimation of moisture.

It is hypothesized that sufficient volatiles will be created during drying as a function of sugar type and level, thus overestimating the moisture content of cheese. The objective of this study was to examine the effects of varying levels of residual lactose and galactose on moisture determination using vacuum oven or microwave-based analyses. Additionally, volatile profiles were examined as a means of validating the conversion of cheese-based reactants into volatile browning reaction products.

\section{MATERIALS AND METHODS}

\section{Cheese Preparation}

Cheddar cheese was manufactured at the University of Wisconsin-Madison dairy processing plant, and commercial low-moisture, part-skim (LMPS) Mozzarella cheese was obtained from a retail store. Cheese samples were kept refrigerated $\left(4^{\circ} \mathrm{C}\right)$ until needed and were used within 1 mo of manufacture. The compositions of Cheddar and Mozzarella cheeses are listed in Table 1. Cheese samples were cut into uniform 1-cm cubes using a cheese cuber (Nemco N55300A; Nemco Inc., Hicksville, $\mathrm{OH}$ ) and blended (approximately 12,000 rpm) for $15 \mathrm{~s}$ (model No. 430; Oster John Manufacturing Company, Milwaukee, WI). Samples of $\alpha$-lactose monohydrate (Fisher Scientific, Fair Lawn, NJ) and galactose (Acros Organics, Geel, Belgium) were dried in a desiccator for $24 \mathrm{~h}$ and then added to cheese as the reducing sugar treatments at levels of $0,1,3$, and $5 \%$ as a total weight of the final experimental unit. Before analysis, blended cheeses were held for $24 \mathrm{~h}$ at $4^{\circ} \mathrm{C}$. The entire experiment was replicated 3 times.

\section{Vacuum Oven Moisture Analysis}

In accordance with a published method for moisture determination (Wehr and Frank, 2004), aluminum dishes (20 mL, $4.4 \mathrm{~cm}$ i.d; Fisher Scientific, Pittsburgh, PA) and fiberglass covers (4.4 cm i.d; Fisher Scientific) were dried in a vacuum oven (model no. 3623; Lab-Line Instruments Inc., Melrose Park, IL) for $1 \mathrm{~h}$ at $100^{\circ} \mathrm{C}$. Each cheese sample $(3 \mathrm{~g})$ was weighed into an aluminum dish on an analytical balance. After the dish was covered with a filter paper, samples were placed in the vacuum oven for $5 \mathrm{~h}$ at $100^{\circ} \mathrm{C}$, and vacuum $(98 \mathrm{mmHg})$ was applied (Cenco model 91506 vacuum pump; Central Scientific Company, Chicago, IL). The samples were cooled in a desiccator to room temperature before weighing.

\section{Microwave Moisture Analyzer Moisture Analysis}

Moisture was determined in parallel to the vacuum oven method using a microwave moisture analyzer (CEM Smart System 5; CEM Corp., Matthews, NC). Fiberglass square sample pads (10 cm; CEM Corp.) were dried for $1 \mathrm{~h}$ at $100^{\circ} \mathrm{C}$ in an oven, and then kept in a desiccator until needed. Cheese samples $(2 \mathrm{~g})$ were evenly distributed between the sample pads, and then placed in the internal balance of the microwave moisture analyzer. Each sample was heated for 2 min at the highest power setting.

\section{Moisture Calculation}

The moisture content was calculated by weight difference after drying. Overestimated moisture (OEM) was calculated as the difference between the percentage moisture of the treated and control samples:

$$
\begin{gathered}
\mathrm{OEM}=\% \text { moisture }(\text { treatment }) \\
-\% \text { moisture }(\text { control }) .
\end{gathered}
$$

\section{Browning Index and Colorimetry}

The browning index (BI) was determined after moisture analysis using the following method (Palombo et

Table 1. Composition ( $\% ; \mathrm{n}=2)$ of Cheddar and low-moisture, partskim (LMPS) Mozzarella cheese for moisture analysis

\begin{tabular}{lccccc}
\hline & \multicolumn{2}{c}{ Cheddar } & & \multicolumn{2}{c}{ LMPS Mozzarella } \\
\cline { 2 - 3 } \cline { 5 - 6 } Item $^{1}$ & Mean & SD & & Mean & SD \\
\hline Moisture & 36.7 & 0.06 & & 47.1 & 0.04 \\
Fat & 31.8 & 0.05 & & 20.8 & 0.09 \\
Protein & 25.9 & 0.02 & & 26.5 & 0.03 \\
Ash & 4.03 & 0.02 & & 3.69 & 0.05 \\
Lactose & 0.1 & 0 & & $<0.1$ & 0 \\
Galactose & $\mathrm{ND}^{2}$ & $\mathrm{ND}$ & & $\mathrm{ND}$ & $\mathrm{ND}$ \\
pH & 5.17 & 0 & & 5.13 & 0 \\
NaCl & 1.76 & 0.01 & & 1.74 & 0.02 \\
\hline
\end{tabular}

${ }^{1}$ Moisture determined by vacuum oven method (Wehr and Frank, 2004); fat by Mojonnier method (Min and Boff, 2003); protein by Kjeldahl method (Chang, 2003); ash by combustion method (Harbers and Nielsen, 2003); lactose and galactose by HPLC method (BeMiller, 2003); pH by quinhydrone golf electrode method (Sadler and Murphy, 2003); and $\mathrm{NaCl}$ by direct titration method (Carpenter and Hendricks, 2003).

${ }^{2}$ Not detected. 
al., 1984). A cheese sample $(1 \mathrm{~g})$ was placed into a 15$\mathrm{mL}$ test tube with $1.5 \mathrm{~mL}$ of distilled water. Then, 0.4 $\mathrm{mL}$ of protease solution [1 mg of enzyme (Streptomyces griseus Type XIV, Sigma Aldrich, St. Louis, MO), and $0.55 \mathrm{mg}$ of $\mathrm{CaCl}_{2}$ in $1 \mathrm{~mL}$ of Tris buffer at $\mathrm{pH} 7.0$ ] was added. Test tubes were held at $45^{\circ} \mathrm{C}$ for $2 \mathrm{~h}$ and then cooled to $25^{\circ} \mathrm{C}$ before analysis. Finally, $0.05 \mathrm{~mL}$ of a 13.3 $M$ TCA solution was added. The resulting solution was centrifuged at $6,300 \times g$ for $20 \mathrm{~min}$ and then gravity filtered (Whatman No. 1 filter paper). Filtrates were placed in a $1-\mathrm{mL}$ cuvette with a $1-\mathrm{cm}$ path length for absorbance analysis. A spectrophotometer (Genesys 20; Thermo Electron Corp., Rochester, NY) was used to determine absorbance (A) at $420 \mathrm{~nm}$ and $550 \mathrm{~nm}$ (the latter measured to account for turbidity; Morales and van Boekel, 1998). These values were used to calculate the BI as $\mathrm{A}_{420 \mathrm{~nm}}-\mathrm{A}_{550 \mathrm{~nm}}$ (Palombo et al., 1984). Higher BI values indicate increased browning. Browning was also characterized using a colorimeter (Chroma Meter CR-300; Konica Minolta, Tokyo, Japan). Samples were measured by placing them directly over the reading port; 3 readings were taken per sample and averaged for each data point. The lightness $\left(\mathbf{L}^{*}\right)$, red-green color $\left(\mathbf{a}^{*}\right)$, and yellow-blue color $\left(\mathbf{b}^{*}\right)$ values were measured using illuminant D65 at a $10^{\circ}$ observer angle (CIE, 1986); the overall color difference from the control $(\Delta \mathbf{E})$ was calculated as follows:

$$
\Delta \mathrm{E}=\sqrt{\left[\left(\Delta \mathrm{L}^{*}\right)^{2}+\left(\Delta \mathrm{a}^{*}\right)^{2}+\left(\Delta \mathrm{b}^{*}\right)^{2}\right]} .
$$

\section{Volatile Recovery and Vacuum Distillation}

All glassware was dried at $48^{\circ} \mathrm{C}$ for at least $24 \mathrm{~h}$. Cheese samples (10 g) were placed in a $100-\mathrm{mL}$, roundbottomed flask and immersed in a hot oil bath at $100^{\circ} \mathrm{C}$. The flask was then connected to a receiving flask, a waste tube, and a rotary vane vacuum pump (Edwards, Ringoes, NJ). The receiving flask and waste tube were held in separate Dewar flasks containing liquid nitrogen. Distillation was carried out for $5 \mathrm{~h}$ under vacuum $(\sim 98 \mathrm{mmHg})$. After distillation, the aqueous distillate of the receiving flask was kept at refrigeration $\left(4^{\circ} \mathrm{C}\right)$ for no longer than $3 \mathrm{~d}$ until volatile analysis.

\section{GC-MS}

Volatile analysis was performed using a gas chromatograph (Agilent 6890N; Agilent Technologies Inc., Palo Alto, CA) fitted with a fused-silica capillary column (RTx-5MS, 30-m long $\times$ 0.25-mm i.d. $\times$ 0.5- $\mu \mathrm{m}$ film thickness; Restek Corp., Bellefonte, PA) and coupled to a mass selective detector (Agilent 5973 MS; Agilent Technologies Inc.). Helium was the carrier gas at a constant flow rate of $1.5 \mathrm{~mL} / \mathrm{min}$. The oven temperature was programmed from 40 to $200^{\circ} \mathrm{C}$ at a rate of $10^{\circ} \mathrm{C} / \mathrm{min}$, with an initial holding time of $5 \mathrm{~min}$. Electron impact ionization was used with a voltage of $70 \mathrm{eV}$. A mass:charge $(\mathrm{m} / z)$ scan range from 29 to 350 atomic mass units was collected at $4.44 \mathrm{scans} / \mathrm{s}$. Aqueous distillate samples $(1 \mu \mathrm{L})$ were injected using the splitless mode. Data analysis was performed using the accompanying software (ChemStation Software Rev. D.02.00 SP1; Agilent Technologies Inc.). The identification of all volatiles reported in this study was made by matching the sample mass spectra with those from a published database (National Institute of Standards and Technology, Version 1.7 Mass Spectral Database; Agilent Technologies Inc.) and comparing retention times with those of standards.

\section{Standards}

Authentic compounds were purchased from SigmaAldrich, and HPLC-grade water (Fisher Scientific, Chicago, IL) was used for dilutions. A mass spectrum is reported for a specific compound for which an authentic standard was not available (Figure 1).

\section{Statistical Analysis}

A full-factorial ANOVA (JMP v. 9.0.0., SAS Institute Inc., Cary, NC) was used to determine the effects of cheese type, sugar type, sugar level, method type, and interactions on OEM, BI, $\mathrm{L}^{*}, \mathrm{a}^{*}, \mathrm{~b}^{*}$, and $\Delta \mathrm{E}$ values with a significance level at $P<0.05$.

\section{RESULTS AND DISCUSSION}

In general, the OEM, BI, and colorimetry values $\left(\mathrm{L}^{*}\right.$, $a^{*}, b^{*}$, and $\Delta E$ ) were significantly affected by cheese type, sugar type, sugar level, method type, and some

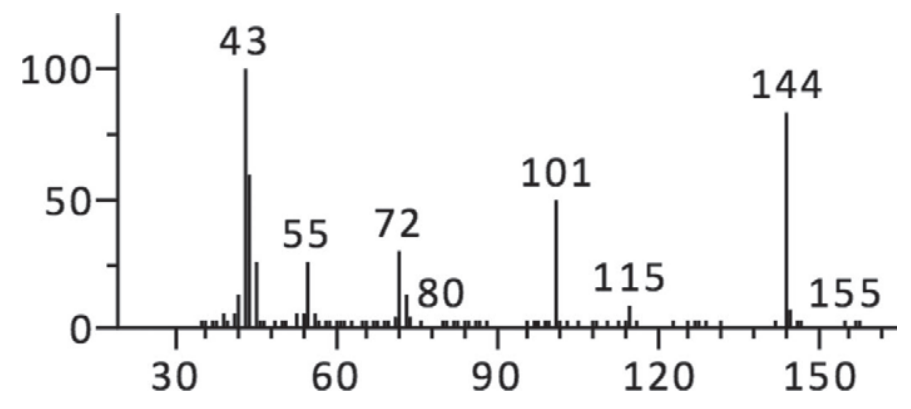

Figure 1. Mass spectrum of tentatively identified pyran [2,3-dihydro-3,5-dihydroxy-6-methyl-4H-pyran-4-one (DDMP)] from Cheddar cheese. The 5 largest peaks (with relative intensities in parentheses) for the compound are as follows: 43 (999), 144 (830), 44 (583), 101 (468), $72(252)$. 
Table 2. Full-factorial ANOVA table including sum of squares (SS), degrees of freedom, F-ratio, and probabilities for overestimated moisture (OEM) content of Cheddar and low-moisture, part-skim (LMPS) Mozzarella cheese

\begin{tabular}{lcccc}
\hline Model factor & SS & df & F-ratio & $P$-value \\
\hline Cheese type (CT) & 0.36 & 1 & 23.00 & $<0.0001$ \\
Sugar type (ST) & 1.31 & 1 & 84.21 & $<0.0001$ \\
Sugar level (SL) & 9.22 & 2 & 3.037 & $<0.0001$ \\
Method type (MT) & 0.41 & 1 & 26.38 & $<0.0001$ \\
CT $\times$ ST & 0.00 & 1 & 0.1430 & 0.7 \\
CT $\times$ SL & 0.09 & 2 & 3.037 & 0.1 \\
CT $\times$ MT & 0.07 & 1 & 4.472 & 0.04 \\
ST $\times$ SL & 0.16 & 2 & 5.056 & 0.01 \\
ST $\times$ MT & 0.02 & 1 & 0.9600 & 0.3 \\
SL $\times$ MT & 0.07 & 2 & 2.391 & 0.1 \\
CT $\times$ ST $\times$ SL & 0.04 & 2 & 1.389 & 0.3 \\
CT $\times$ ST $\times$ MT & 0.03 & 1 & 1.952 & 0.2 \\
CT $\times$ SL $\times$ MT & 0.10 & 2 & 3.224 & 0.05 \\
ST $\times$ SL $\times$ MT & 0.07 & 2 & 2.214 & 0.1 \\
CT $\times$ ST $\times$ SL $\times$ MT & 0.04 & 2 & 1.222 & 0.3 \\
\hline
\end{tabular}

interactions (Table 2). The main effects and notable interactions for OEM are discussed below.

\section{Cheese Type}

Overall OEM averages of Cheddar and Mozzarella cheeses were significantly different at 0.94 and $0.80 \%$, respectively. Correspondingly, the BI averages of Cheddar and Mozzarella cheeses were different at 1.2 and 0.79 , respectively. The $\mathrm{L}^{*}, \mathrm{a}^{*}$, and $\mathrm{b}^{*}$ averages for galactose and lactose were different at 40.3 and $42.5,14.7$ and 14.4, and 27.1 and 29.7, respectively $(P<0.05)$. The $\Delta \mathrm{E}$ averages of Cheddar and Mozzarella cheese were different at 37.9 and 31.4, respectively $(P<0.05)$. Each of these outcomes suggests that Cheddar cheese is more susceptible to browning-based OEM than Mozzarella. This susceptibility may result from potentially higher concentrations of reaction substrates from increased levels of proteolysis and lipolysis in Cheddar. Additionally, Mozzarella has a higher moisture content than Cheddar cheese (Table 1). Studies have shown that moisture acts as both solvent and reactant in Maillard browning reactions (van Boekel, 2001). During the first stages of browning mechanisms, moisture is essential for Maillard reactions. However, high moisture content may decrease browning reaction rates as a result of diluted reactants. Both BI and colorimetry data support the hypothesis that the OEM in cheese results from Maillard browning reactions.

The OEM averages for galactose and lactose were significantly different at 1.0 and $0.74 \%$, respectively. The BI averages for galactose and lactose were significantly different at 1.4 and. 0.56 , respectively. The $\mathrm{L}^{*}, \mathrm{a}^{*}$, and $\mathrm{b}^{*}$ averages for galactose and lactose were significantly different at 33.7 and 49.0, 14.6 and 14.5, and 22.1 and 34.7 , respectively $(P<0.05)$. The $\Delta \mathrm{E}$ averages for ga- lactose and lactose were significantly different at 70.4 and 62.7 , respectively $(P<0.05)$. Possible explanations for higher OEM and browning with galactose include the higher molar concentration and higher reactivity (Dattatreya et al., 2010). Monosaccharides are known to increase the initial rate of browning as a function of the rate at which the sugar's ring opens to present the reactive, reducing carbonyl group to the amine group (Overend et al., 1961).

The OEM averages for sugar levels $1 \%, 3 \%$, and $5 \%$ were significantly different at $0.45,0.85$, and $1.3 \%$, respectively. The BI averages for sugar levels $1 \%, 3 \%$, and $5 \%$ were significantly different at $0.53,0.96$, and 1.5 , respectively. The $\mathrm{L}^{*}, \mathrm{a}^{*}$, and $\mathrm{b}^{*}$ averages for sugar levels $1 \%, 3 \%$, and $5 \%$ were all significantly different at 49.5, 39.6, and $35.0\left(\mathrm{~L}^{*}\right) ; 17.2,14.1$, and $12.3\left(\mathrm{a}^{*}\right)$; and $35.8,26.5$, and $22.9\left(\mathrm{~b}^{*}\right)$, respectively (Table 3 ). The $\Delta \mathrm{E}$ averages for sugar levels $1 \%, 3 \%$, and $5 \%$ were 62.8 , 67.2, and 69.7, respectively. As predicted, the OEM of samples increased with increasing sugar levels due to an increase in reducing sugar substrate and proximity to the amine groups to initiate Maillard browning reactions (Warmbier et al., 1976).

\section{Method Type}

The OEM averages for vacuum oven and microwave moisture analyzer methods were significantly different at 0.80 and $0.95 \%$, respectively. The BI averages for vacuum oven and microwave methods were significantly different at 0.74 and 1.2 , respectively (Table 4 ). The $L^{*}, a^{*}$, and $b^{*}$ averages for vacuum oven and microwave moisture analyzer were significantly different at 48.9 and 33.8, 15.0 and 14.1, and 33.5 and 23.3 , respectively. The $\Delta \mathrm{E}$ values for vacuum oven and microwave moisture analyzer were significantly 
Table 3. Mean $(\mathrm{n}=3)$ and standard deviation (SD) of overestimated moisture (\%) content of Cheddar and low-moisture, part-skim (LMPS) Mozzarella cheese with added lactose and galactose using vacuum oven and microwave moisture analyses

\begin{tabular}{|c|c|c|c|c|}
\hline \multirow[b]{2}{*}{ Treatment } & \multicolumn{2}{|c|}{ Vacuum oven } & \multicolumn{2}{|c|}{ Microwave } \\
\hline & Mean & $\mathrm{SD}$ & Mean & $\mathrm{SD}$ \\
\hline \multicolumn{5}{|l|}{ Cheddar } \\
\hline \multicolumn{5}{|c|}{ Lactose (\%) } \\
\hline 1 & 0.40 & 0.04 & 0.50 & 0.2 \\
\hline 3 & 0.72 & 0.04 & 0.83 & 0.1 \\
\hline 5 & 1.1 & 0.09 & 1.2 & 0.2 \\
\hline \multicolumn{5}{|c|}{ Galactose (\%) } \\
\hline 1 & 0.64 & 0.06 & 0.65 & 0.1 \\
\hline 3 & 1.0 & 0.07 & 1.2 & 0.2 \\
\hline 5 & 1.5 & 0.03 & 1.5 & 0.2 \\
\hline \multicolumn{5}{|c|}{ LMPS Mozzarella } \\
\hline \multicolumn{5}{|c|}{ Lactose $(\%)$} \\
\hline 1 & 0.20 & 0.09 & 0.38 & 0.1 \\
\hline 3 & 0.63 & 0.05 & 0.66 & 0.2 \\
\hline 5 & 0.97 & 0.09 & 1.2 & 0.2 \\
\hline \multicolumn{5}{|c|}{ Galactose (\%) } \\
\hline 1 & 0.39 & 0.02 & 0.56 & 0.1 \\
\hline 3 & 0.75 & 0.06 & 0.99 & 0.1 \\
\hline 5 & 1.2 & 0.02 & 1.8 & 0.2 \\
\hline
\end{tabular}

different at 25.2 and 43.9 , respectively (Table 4). A possible explanation for higher OEM with microwave moisture analyzer is that the application of microwave energy can cause excessive heating due to nonuniform heat and mass transfer (Datta, 1990). Unlike conventional ovens, microwaves penetrate the interior of the sample, thus allowing for faster transfer of moisture in a shorter period of time. However, continued heating of the sample can lead to excessive temperature increases, resulting in pyrolysis. Microwave drying may also not be as precise as conventional oven methods because of variations in temperature distribution within the sample depending on sample size, geometry, and location in the oven (Ni and Datta, 1999; Vadivambal and Jayas, 2010).

\section{Interactions}

We detected 3 significant interaction effects for all tested variables (Table 2). Based on the experimental design, there were a total of 11 interaction terms. Because OEM is the key dependent variable, the discussion of interactions is limited to this dependent variable. Even though the interactions were significant, statistically, these interactions had only minor, practical effects within the scope of the parameters studied; thus, only the 2-way interactions are discussed.

The OEM of sugar type was more affected at a higher sugar level, resulting in a sugar type $\times$ sugar level interaction (Figure 2), and more browning with higher sugar concentrations (Figure 3). The following causes are offered as potential explanations for this interaction. As the browning reactions proceed, more amine groups are deprotonated, thus increasing the $\mathrm{pH}$. In general, the rate and extent of Maillard browning is catalyzed by increasing pH (Ashoor and Zent, 1984). The amount of acyclic or reducing form of sugar also affects the rate of browning and increases with increasing $\mathrm{pH}$, which may also increase the rate of Maillard browning (Kannane and Labuza, 1985).

The OEM of cheese types was more affected by vacuum oven method than by the microwave-based method, resulting in a cheese type $\times$ method type interaction (Figure 2). Possible explanations include melting characteristics of cheese, which is defined as the ease and extent to which cheese will flow upon heating. Studies suggest that increased temperature lowers cheese meltability due to loss of fat and moisture from the cheese matrix (Wang and Sun, 2002), possibly as a result of increased protein-protein interactions.

\section{Cheddar Volatile Analysis}

Volatile compounds found using GC-MS in Cheddar cheese are reported in Table 5 . A total of 16 compounds were identified, including acids, alcohols, aldehydes, ketones, pyrans, and pyrroles. Notable volatiles in lactose-treated cheese included 3-methylbutanal, benzeneacetaldehyde, 2-nonanone, 3-hydroxy-2-methyl-4Hpyran-4-one (maltol), and 2,3-dihydro-3,5,dihydroxy6-methyl-4H-pyran-4-one (DDMP). The volatile profile of galactose-treated cheese was similar to that of lactose-treated cheese, with a few exceptions. Galactose-treated cheese yielded no maltol, but contained 2 -oxopropanal (methylglyoxal) and 1-1H-pyrrol-2-ylethanol (2-acetylpyrrole). 


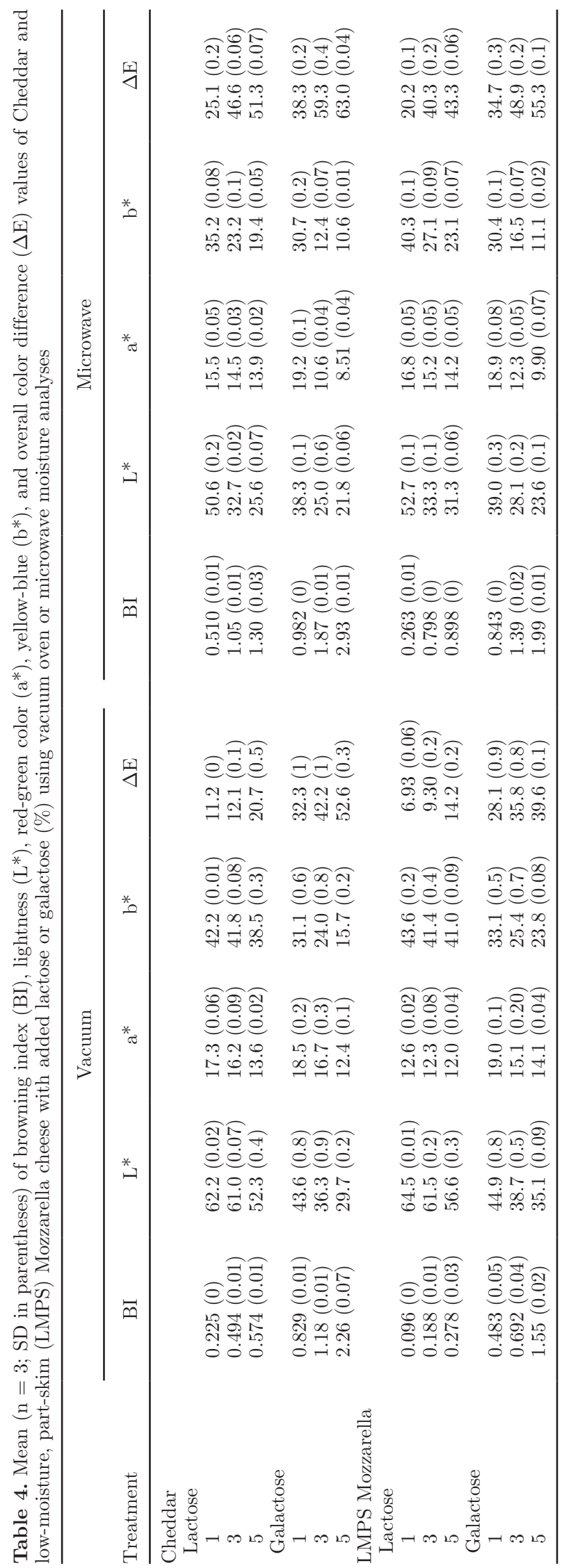

A total of 5 acids were identified in all samples, including acetic, butanoic, hexanoic, octanoic, and decanoic acids (Table 5). These acids are common FFA in many cheese varieties and primarily result from the hydrolysis of milk fat. Excessive hydrolysis of milk fat may release higher amounts of FFA and also potentially contribute to the overestimation of cheese moisture. Acetic acid can also be formed by $\mathrm{C} 2-\mathrm{C} 3$ cleavage of 1-deoxy-2,3-hexodiulose (1-deoxysone), resulting from the degradation of the ARP by 2,3-enolization in Maillard browning (Davidek et al., 2002).

A total of 4 aldehydes were identified, including 3-methylbutanal, benzeneacetaldehyde, nonanal, and methylglyoxal (Table 5). Nonanal was identified in all samples. The compounds 3-methylbutanal, benzeneacetaldehyde, and methylglyoxal were identified in both lactose- and galactose-treated samples. However, methylglyoxal was only identified in galactose-treated samples. The compounds 3-methylbutanal and benezenealdehyde are products of Strecker degradation in Maillard browning (Schonberg and Moubacher, 1952; Patton, 1955). Strecker degradation involves oxidative degradation of $\alpha$-amino acids by $\alpha$-dicarbonyl intermediates. Such reactions form unstable Schiff's bases, which decarboxylate to form enamines and $\mathrm{CO}_{2}$. Subsequent hydrolysis of enamines forms Strecker aldehydes and $\alpha$-aminoketones. The aldehydes 3-methylbutanal and benzeneacetaldehyde were identified in sugar-treated samples, most likely resulting from Maillard browning reactions. Methylglyoxal is a crucial $\alpha$-dicarbonyl intermediate in cross-linking of proteins by reducing sugars in Maillard browning. Strecker degradation of amino acids with methylglyoxal can result in aminoacetone. The formation of aminoacetone can undergo spontaneous condensation with another aminoacetone to produce heterocyclic compounds, such as pyrazines, which are advanced Maillard browning products at the final stages of Maillard browning. Methylglyoxal is also produced by certain lactic acid bacteria as a byproduct of sugar fermentation (Urbach, 1995).

The ketone 2-heptanone was identified in all samples, whereas 2-nonanone was identified only in lactose- or galactose-treated cheese (Table 5). Formation of ketones involves oxidation of fatty acids to $\beta$-ketoacids, which are then decarboxylated to corresponding ketones with 1 fewer carbon atom (Hawke, 1966). Ketones may react with amino acids, yielding Maillard browning products (Namiki, 1988). The compound 2-nonanone has been found in heat-processed milk products (Badings et al., 1981) and it would follow that the carbonyl moiety of this or other ketones would be available as a reactant in subsequent Maillard browning pathways.

A total of 3 pyran compounds were identified (Table $5)$. The compound 3-hydroxy-2-methyl-4H-pyran-4-one 
a
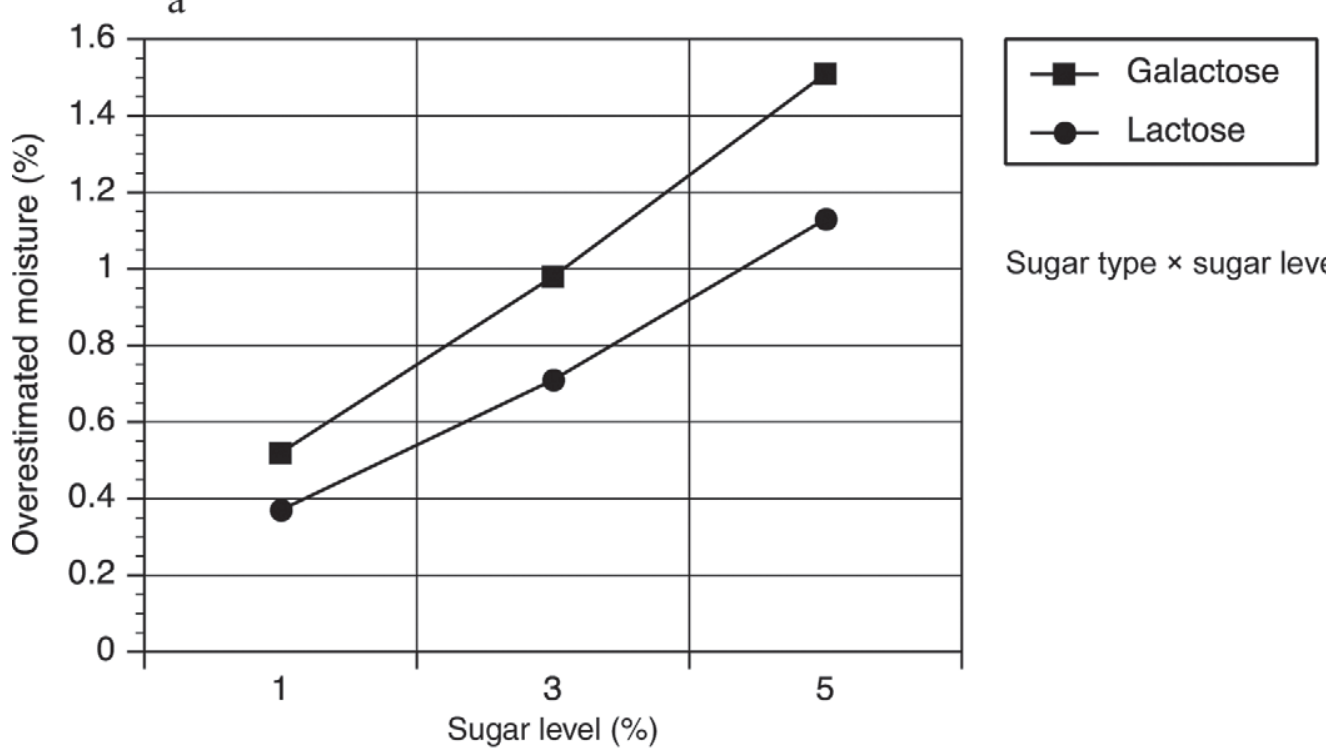

Sugar type $\times$ sugar level

b
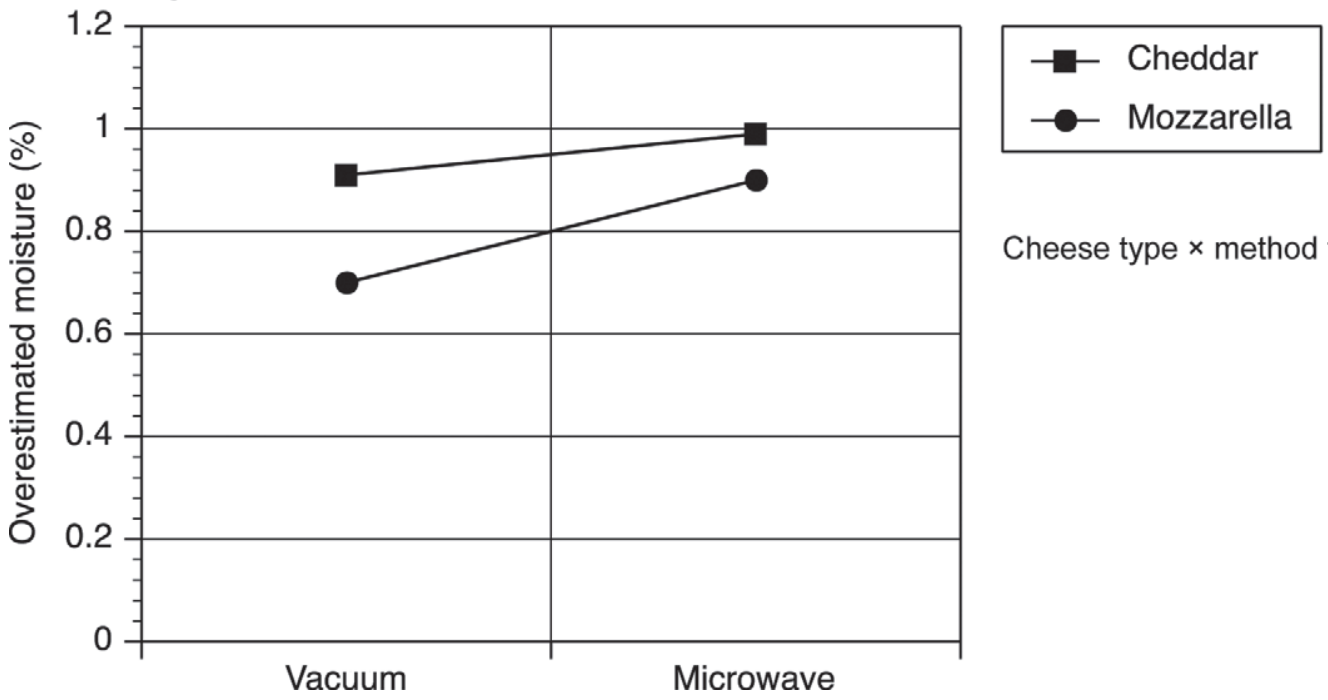

Cheese type $\times$ method type

Figure 2. Graphical representations of significant 2-way interactions affecting overestimated moisture (OEM).

(maltol) was identified in the lactose-treated sample. The compound DDMP was identified in both lactoseand galactose-treated samples, and tetrahedro-6-pentyl-2H-pyran-2-one ( $\delta$-decalactone) was identified in all samples. There are 2 possible pathways for maltol from lactose and lysine. The compound 1-deoxysone, formed from 2,3-enolization of ARP, can produce a pyranoid intermediate to form maltol. A second pathway involves $\beta$-elimination of 1-deoxysone to form maltol, which has been found in heated milk (van Boekel, 1998). Previous studies suggest that maltol is not formed in significant quantities in reactions with glucose or galactose and, therefore, is only present in the lactose-treated sample (Patton, 1950). The compound DDMP is a reductone, which can be formed through fragmentation of 1-deoxysone; it may also undergo an acid-catalyzed rearrangement to give isomaltol, a furan derivative (Shaw et al., 1971). In addition, DDMP has previously been found in sugar-casein systems, and is therefore identified in sugar-treated samples (Brands and van Boekel, 2001). The compound $\delta$-decalactone is a cyclic ester resulting from intramolecular esterification of 5-hydroxy acids. At high temperatures, esterified hydroxyl acids are hydrolyzed from the glycerides to form a free hydroxyl acid, followed by lactonization to form lactones (Jolly and Kosikowski, 1975). Unsaturated fatty acids can also hydrate to hydroxyl acids through $\beta$-oxidation to produce lactones (Cadwallader and Singh, 1997). 
Table 5. Qualitatively identified volatile compounds (by GC-MS) in Cheddar cheese (control, with 5\% lactose, and with 5\% galactose)

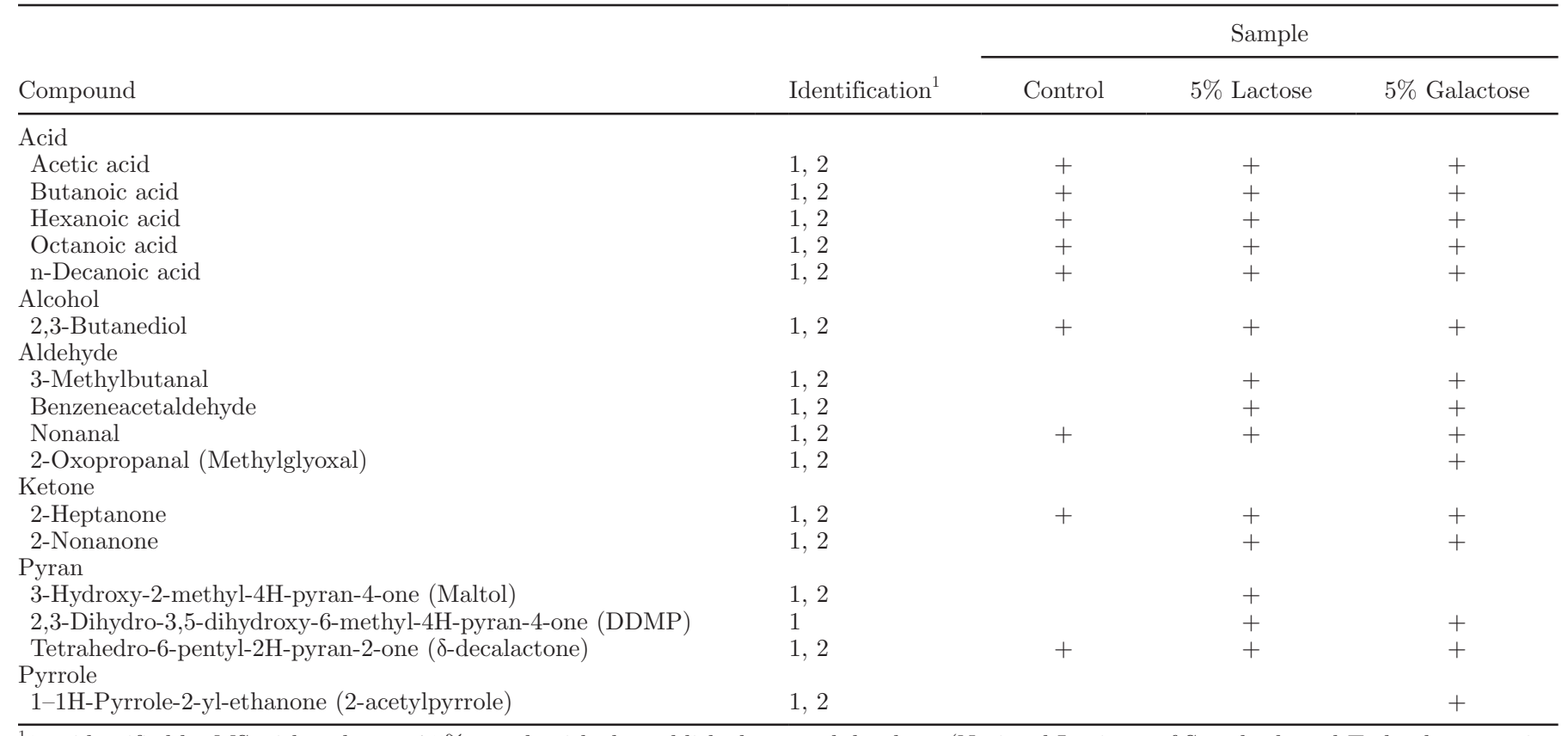

${ }^{1} 1=$ identified by MS with at least a $75 \%$ match with the published spectral database (National Institute of Standards and Technology; version 1.7 Mass Spectral Database; Agilent Technologies Inc., Palo Alto, CA); 2 = identified by comparison of retention times of authentic standards.

Lactones are common flavor compounds in cheese and therefore identified in all samples.

A single pyrrole compound, 1-1H-pyrrol-2-yl-ethanone (2-acetylpyrrole), was tentatively identified only in galactose-treated samples (Table 5). During Maillard browning, the formation of ARP undergoes further 1,2-enolization and dehydration to form 2-acetylpyrrole under slightly acidic or neutral conditions (Hodge, 1953; Shaw and Berry, 1977). Under basic conditions, protons in sugar molecules are affected to form deoxyhexulose and hexosulose-3-ene intermediates. These intermediates react with amino acids to produce pyrrole derivatives. The compound 2-acetylpyrrole is an advanced Maillard browning product yielded in the final stages of Maillard browning (Milic and Piletic, 1984) and therefore indicates more intense browning in galactose-treated sample.

\section{Mozzarella Volatile Analysis}

Volatile compounds found in LMPS Mozzarella cheese are reported in Table 6 . A total of 11 compounds were identified, including acids, alcohols, aldehydes, ketones, and furans. The notable volatile difference in lactosetreated cheese from the control was the presence of 3 -methybutanal and benzeneacetaldehyde. The volatile profile of lactose-treated cheese was similar to that of galactose-treated cheese, but yielded no 2-furaldehyde (furfural).
A total of 3 acids and 1 alcohol were identified in all samples, including acetic, octanoic, n-decanoic acids, and 2,3-butanediol (Table 6). As with Cheddar cheese, FFA and alcohols are common volatiles formed from hydrolysis of milk fat and citrate metabolism, respectively.

A total of 4 aldehydes were identified (Table 6). 3-Methylbutanal and benzeneacetaldehyde were identified in lactose- and galactose-treated samples. Nonanal and heptanal were identified in all samples. The compounds 3-methylbutanal and benzenealdehyde are known Strecker degradation products (Schonberg and Moubacher, 1952; Patton, 1955). Nonanal and heptanal are commonly identified in Mozzarella cheese from bovine or water buffalo milk and are straight-chain aldehydes, which are potential products of $\beta$-oxidation of unsaturated fatty acids (Collomb and Spahni, 1997). Straight-chain aldehydes may also form from Strecker degradation in Maillard browning (Hodge, 1953).

Two ketones, 2-heptanone and 2-nonanone, were identified in all samples (Table 6). Ketones are common constituents in dairy products and they are generally related to lipolysis or oxidation of fatty acids. Ketones may react with amino acids, yielding Maillard browning products (Namiki, 1988).

One furan compound, furfural, was identified in the galactose-treated sample (Table 6). Furfurals are formed from 1,2-enolization of ARP. The reaction for 1,2-enolization is promoted by the withdrawal of electrons from 


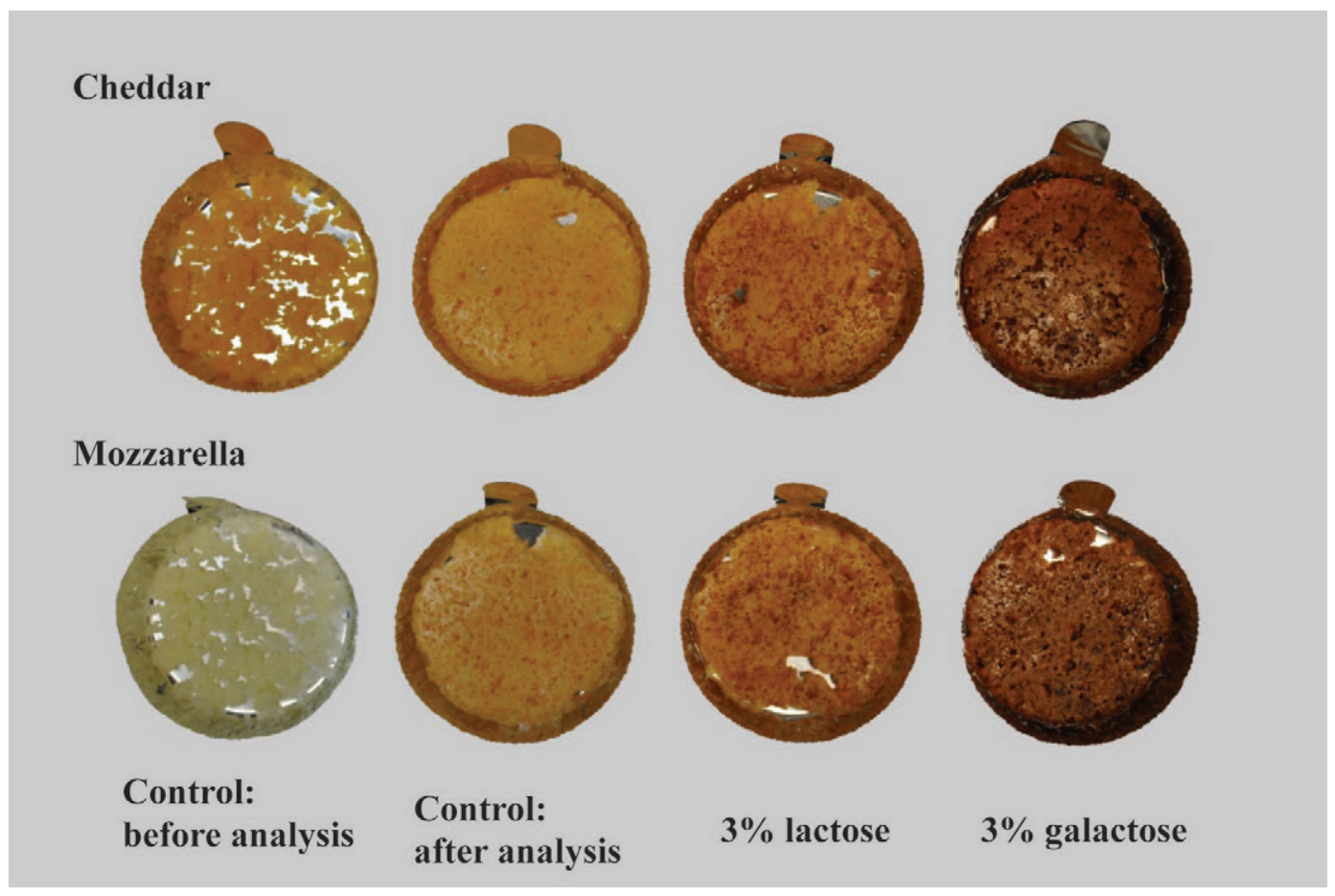

Figure 3. Representative samples of Cheddar cheese and low-moisture, part-skim (LMPS) Mozzarella cheeses before and after the vacuum oven analysis without and with $3 \%$ added lactose or galactose. Color version available in the online PDF.

$\mathrm{C} 1$ of the sugar residue by the positively charged nitrogen atom. The reaction proceeds with $\beta$-elimination of the C3 hydroxyl group, followed by hydrolysis of the amine group, and forming an intermediate called 3-deoxysone (Namiki, 1988). Further reaction yields furaldehyde compounds, such as furfural (O'Brien, 1997). Furfural was identified only in galactose-treated samples, possibly due to extensive Maillard browning compared with the lactose-treated sample.

\section{CONCLUSIONS}

Cheeses vary in their levels of residual lactose or sugar as a function of several factors, including stan-

Table 6. Qualitatively identified volatile compounds (by GC-MS) in low-moisture, part-skim (LMPS) Mozzarella cheese (control, with $5 \%$ lactose, and with $5 \%$ galactose)

\begin{tabular}{|c|c|c|c|c|}
\hline \multirow[b]{2}{*}{ Compound } & \multirow[b]{2}{*}{ Identification $^{1}$} & \multicolumn{3}{|c|}{ Sample } \\
\hline & & Control & $5 \%$ Lactose & $5 \%$ Galactose \\
\hline \multicolumn{5}{|l|}{ Acid } \\
\hline Acetic acid & 1,2 & + & + & + \\
\hline Octanoic acid & 1,2 & + & + & + \\
\hline n-Decanoic acid & 1,2 & + & + & + \\
\hline \multicolumn{5}{|l|}{ Alcohol } \\
\hline 2,3-Butanediol & 1,2 & + & + & + \\
\hline \multicolumn{5}{|l|}{ Aldehyde } \\
\hline 3-Methylbutanal & 1,2 & & + & + \\
\hline Benzeneacetaldehyde & 1,2 & & + & + \\
\hline Nonanal & 1,2 & + & + & + \\
\hline Heptanal & 1,2 & + & + & + \\
\hline \multicolumn{5}{|l|}{ Ketone } \\
\hline 2-Heptanone & 1,2 & + & + & + \\
\hline 2-Nonanone & 1,2 & + & + & + \\
\hline \multicolumn{5}{|l|}{ Furan } \\
\hline 2-Furaldehyde (furfural) & 1,2 & & & + \\
\hline
\end{tabular}

${ }^{1} 1$ = identified by MS with at least a $75 \%$ match with the published spectral database (National Institute of Standards and Technology; version 1.7 Mass Spectral Database; Agilent Technologies Inc., Palo Alto, CA); 2 $=$ identified by comparison of retention times of authentic standards. 
dardization with lactose-containing milk solids (e.g., nonfat dry milk powder) or even membrane technologies wherein lactose is concentrated. Additionally, some bacterial starter cultures such as may be used in Mozzarella manufacture may preferentially utilize the glucose unit of lactose, wherein the highly reactive galactose sugar may accumulate. This study demonstrated that the OEM of cheese can be affected by several factors, including cheese type, sugar type, sugar level, method type, and numerous interactions. In general, OEM increased in the cheese with galactose treatment, higher sugar level, and microwave-based drying, establishing the need to consider such factors in cheese moisture determination. Identification of Strecker degradation and fragmentation products in sugar-treated Cheddar and Mozzarella cheeses provides chemical evidence that 2,3-enolization of ARP, followed by Strecker degradation, is the plausible pathway under conditions of cheese moisture determination. Identification of 2-acetylpyrrole and furfural provides evidence that 1,2-enolization is another plausible pathway. Other reactions, such as triglyceride hydrolysis and reactions with lipid oxidation products, may also contribute to the overall loss of mass during thermal-based moisture determination. Although such spontaneous reactions may be difficult to control during analysis, methods of moisture analysis may need to be adjusted to account for reactions capable of yielding volatile compounds lost during the heating process. Such adjustments could include the use of lower temperatures during drying, higher vacuum levels or the addition of chemical compounds that may interfere with or impede browning reactions.

\section{ACKNOWLEDGMENTS}

We express our appreciation to Coordenaçao de Aperfeiçoamento de Pessoal de Nível Superior (CAPES)-Brazil Estágio Sênior Process no. 18183/123 for financial support.

\section{REFERENCES}

AOAC. 1990. Official Methods of Analysis. Vol. I. 15th ed. Association of Official Analytical Chemists (AOAC), Arlington, VA.

Ashoor, S., and J. Zent. 1984. Maillard browning of common amino acids and sugars. J. Food Sci. 49:1206-1207.

Badings, H. T., J. J. G. van der Pol, and R. Neeter. 1981. Aroma compounds which contribute to the difference in flavour between pasteurized milk and UHT milk. Pages 683-692 in Flavour '81. P. Schreier, ed. Walter de Gruyter, New York, NY.

BeMiller, J. N. 2003. Carbohydrate analysis. Pages 143-174 in Food Analysis. 3rd ed. S. S. Nielsen, ed. Springer LLC, New York, NY.

Brands, C. M., and M. A. J. S. van Boekel. 2001. Reactions of monosaccharides during heating of sugar-casein system: Building of a reaction network model. J. Agric. Food Chem. 49:4667-4675.

Cadwallader, K. R., and T. K. Singh. 1997. Flavours and off-flavours in milk and dairy products. Pages 631-690 in Advanced Dairy
Chemistry. Vol. 3. Lactose, Water, Salts and Minor Consistituents 3rd ed. P. L. H. McSweeney and P. F. Fox, ed. Springer-Verlag, New York, NY.

Carpenter, C. E., and D. G. Hendricks. 2003. Mineral analysis. Pages 198-206 in Food Analysis. 3rd ed. S. S. Nielsen, ed. Springer LLC, New York, NY.

Chang, S. K. C. 2003. Protein analysis. Pages 131-142 in Food Analysis. 3rd ed. S. S. Nielsen, ed. Springer LLC, New York, NY.

CIE. 1986. Colorimetry. 2nd ed. Commission International de l'Eclairage (CIE). CIE Central Bureau, Vienna, Austria.

Collomb, M., and M. Spahni. 1997. Determination of milk fat oxidation: A critical appraisal. Agrarforschung Schweiz 4:423-426.

Datta, A. K. 1990. Heat and mass transfer in the microwave processing of food. Chem. Eng. Prog. 86:47-53.

Dattatreya, A., W. Lee, and S. Rankin. 2010. Short communication: Presence of galactose and glucose promotes browning of sweet whey powder. J. Dairy Sci. 93:2354-2357.

Davidek, T., N. Clety, S. Aubinand, and I. Blank. 2002. Degradation of Amadori compound N-(1-deoxy-D-fructos-1-yl)glycine in aqueous model systems. J. Agric. Food Chem. 50:5472-5479.

Ferretti, A., and V. P. Flanagan. 1971. Lactose-casein (Maillard) browning system: Volatile components. J. Agric. Food Chem. $19: 245-249$

Harbers, H. L., and S. S. Nielsen. 2003. Ash analysis. Pages 103-112 in Food Analysis. 3rd ed. S. S. Nielsen, ed. Springer LLC, New York, NY.

Hawke, J. C. 1966. The formation and metabolism of methyl ketones and related compounds. J. Dairy Sci. 33:225-243.

Hodge, J. 1953. Chemistry of browning reactions in model systems. J. Agric. Food Chem. 1:928-943.

Jolly, R. C., and F. V. Kosikowski. 1975. Quantification of lactones in ripening pasteurized milk blue cheese containing added microbial lipases. J. Agric. Food Chem. 23:1175-1176.

Kannane, A., and T. P. Labuza. 1985. Change in available lysine loss reaction in fish flour due to an $\mathrm{a}_{\mathrm{w}}$ change induced by a temperature shift. J. Food Sci. 50:582-584.

Labuza, T. P. 1994. Interpreting the complexity of the kinetics of the Maillard reaction. Pages $176-181$ in Maillard Reactions in Chemistry, Food and Health. T. P. Labuza, G. A. Reineccius, V. M. Monnier, J. O'Brien, and J. W. Baynes, ed. Royal Society of Chemistry, Cambridge, UK.

Milic, B. L., and M. V. Piletic. 1984. The mechanism of pyrrole, pyrazine and pyridine formation in non-enzymatic browning reaction. Food Chem. 13:165-180.

Min, D. B., and J. M. Boff. 2003. Crude fat analysis. Pages 113-130 in Food Analysis. 3rd ed. S. S. Nielsen, ed. Springer LLC, New York, NY

Morales, F. J., and M. A. J. S. van Boekel. 1998. A study on advanced Maillard reaction in heated casein/sugar solutions: Colour formation. Int. Dairy J. 8:907-915.

Namiki, M. 1988. Chemistry of Maillard reactions: Recent studies on the browning reaction mechanism and the development of antioxidants and mutagens. Adv. Food Res. 32:115-184.

Ni, H., and A. K. Datta. 1999. Moisture loss as related to heating uniformity in microwave processing of solid foods. J. Food Process Eng. 22:367-382.

O'Brien, J. 1997. Reaction chemistry of lactose: Non-enzymatic degradation pathways and their significance in dairy products. Pages 155-216 in Advanced Dairy Chemistry. 2nd ed. Vol. 3. P. F. Fox, ed. Chapman \& Hall, London, UK.

Overend, W., A. Peacocke, and J. Smith. 1961. Reactions at position 1 of carbohydrates. Part I. The polarographic reduction of carbohydrates. J. Chem. Soc. 3487-3497.

Palombo, R., A. Gertler, and I. Saguy. 1984. A simplified method for determination of browning in dairy powders. J. Food Sci. 49:1609-1613.

Patton, S. 1950. The formation of maltol in certain carbohydrateglycine systems. J. Biol. Chem. 184:131-134.

Patton, S. 1955. Browning and associated changes in milk and its products. J. Dairy Sci. 38:457-478. 
Sadler, G. D., and P. A. Murphy. 2003. pH and titratable acidity. Pages 207-226 in Food Analysis. 3rd ed. S. S. Nielsen, ed. Springer LLC, New York, NY.

Schonberg, A., and R. Moubacher. 1952. The Strecker degradation of $\alpha$-amino acids. Chem. Rev. 50:261-277.

Shaw, P. E., and R. E. Berry. 1977. Hexose-amino acid dehydration studies involving formation of pyrroles, furans, and other low molecular weight products. J. Agric. Food Chem. 25:641-644.

Shaw, P. E., J. H. Tatum, and R. E. Berry. 1971. 2,3-Dihydro-3,5-dihydroxy-6-methyl-4-H-pyran-4-one, a degradation product of hexose. Carbohydr. Res. 16:207-211.

Urbach, G. 1995. Contribution of lactic acid bacteria to flavor compound formation in dairy products. Int. Dairy J. 5:877-903.

Vadivambal, R., and D. S. Jayas. 2010. Non-uniform temperature distribution during microwave heating of food materials - A review. Food Bioprocess. Technol. 3:161-171. van Boekel, M. A. J. S. 1998. Effect of heating on Maillard reactions in milk. Food Chem. 62:403-414.

van Boekel, M. A. J. S. 2001. Kinetic aspects of the Maillard reaction: A critical review. Nahrung 45:150-159.

Wang, H. H., and D. W. Sun. 2002. Melting characteristics of cheese: Analysis of effects of cooking conditions using computer vision technology. J. Food Eng. 51:305-310.

Warmbier, H. C., R. A. Schnickels, and T. P. Labuza. 1976. Effect of glycerol on nonenzymatic browning in a solid intermediate moisture model food system. J. Food Sci. 41:528-531.

Wehr, M., and J. Frank. 2004. Moisture and solids tests. Pages 442 445 in Standard Methods for the Examination of Dairy Products. 17th ed. American Public Health Association, Baltimore, MD. 